\title{
Strategi Pengembangan Ekowisata dengan Konsep Community Based Tourism (CBT) di Pantai Kawaliwu Desa Sinar Hading, Flores Timur
}

\author{
Dati Nawastuti ${ }^{1 *}$, Zefirinus Kada Lewoema ${ }^{2}$ \\ ${ }^{1}$ Program Studi Teknologi Hasil Perikanan, Fakultas Teknologi, \\ Institut Keguruan dan Teknologi Larantuka, Jalan Ki Hajar Dewantara, Larantuka, \\ Flores Timur Kode Pos 86212, Nusa Tenggara Timur, Indonesia \\ ${ }^{2}$ Kantor Camat Lewolema, Pemerintah Kabupaten Flores Timur, Provinsi Nusa Tenggara Timur \\ Jl. Bantala, Kawaliwu, Lewolema, Flores Timur, Nusa Tenggara Timur, Indonesia \\ "Corresponding author, email: nawastuti.dati78@gmail.com
}

\begin{abstract}
ABSTRAK: Ekowisata adalah perjalanan ke kawasan alam yang relatif masih asli dan tidak tercemar dengan minat khusus untuk mempelajari, mengagumi, dan menikmati pemandangan, tumbuhan, satwa liar dan budaya. Penelitian ini bertujuan untuk mengidentifikasi potensi-potensi ekowisata yang ada di Desa Sinar Hading, menganalisis ekowisata dengan menerapkan CBT (Community Based Tourism), dan mengidentifikasi usaha dan partisipasi masyarakat dalam pembangunan pariwisata dengan menerapkan CBT. Penelitian ini dilaksanakan di Desa Sinar Hading Kecamatan Lewolema Kabupaten Flores Timur pada bulan Maret 2019. Data-data dikumpulkan melalui wawancara terstruktur. Pertanyaan-pertanyaan diajukan berdasarkan dimensi-dimensi pada CBT yakni dimensi ekonomi, dimensi sosial, dimensi budaya dan dimensi lingkungan. Subyek penelitian ditentukan dengan menggunakan teknik penentuan secara sengaja. Dalam teknik pengambilan data tersebut, beberapa stakeholder dipilih berdasarkan pengaruh dan kepentingan dalam pariwisata di Pantai Kawaliwu yang terletak di Desa Sinar Hading. Pengolahan data dilakukan secara deskriptif. Data yang terangkum dihitung di dalam persentase dan dibahas. Disimpulkan bahwa potensi-potensi ekowisata di Desa Sinar Hading terdiri atas potensi alam, manusia, sosial, dan budaya yang semuanya memberikan dampak nyata bagi pariwisata; dimensidimensi ekonomi, sosial, budaya, dan lingkungan saling berkaitan dan memengaruhi secara individual maupun secara kolektif; dan usaha-usaha masyarakat masih berskala kecil dan bersifat sambilan dan belum merupakan usaha pokok meskipun berpotensi memajukan pariwisata apabila dikelola secara profesional.
\end{abstract}

Kata kunci: Ekowisata; konservasi; potensi; produk; unggulan

\section{Ecotourism Development Strategy with the Concept of Community Based Tourism (CBT) on Kawaliwu Beach, Sinar Hading Village, East Flores}

ABSTRACT: Eco-tourism is a trip to natural areas that are relatively pristine and not polluted with special interest to learn, admire, and enjoy the scenery, plants, wildlife and culture. This research aims to identify eco-tourism potencies in Sinar Hading Village, to analyze eco-tourism by applying Community Based Tourism (CBT), and to identify efforts and community participation in ecotourism development by applying CBT. The research was conducted in Sinar Hading Village, Sub Regency of Lewolema, East Flores Regency, in March 2019. Data were collected by using structured interview. Questions are posted based on dymensions of CBT such as economy dymension, social dymension, culture dymension and environment dymension. The research units were determined by using purpossive sampling. In this data collecting, several stakeholders were chosen based on their influence and their interest on tourism in Kawaliwu Beach which is located in Sinar Hading Village. Data were analyzed by using descriptive analysis, composed in percentage and then discussed. It is concluded that eco-tourism potencies in Sinar Hading Village are nature, men, social, and culture which give significant impact on tourism; social, economy, culture and environment dymensions are interconnected and influence both individually and collectively; and community business characters are small scale and part time and have not become main job although they are potencial to enhance tourism if it is managed professionally.

Keywords: Ecotourism; conservation; potency; product; advance 


\section{PENDAHULUAN}

Ekowisata adalah perjalanan dan kunjungan yang bertanggungjawab terhadap lingkungan yang relatif tidak mengganggu kawasan alam dalam hal menikmati alam, studi, dan apresiasi alam termasuk aspek budayanya untuk menunjang konservasi yang semua aktivitas pengunjung berdampak negatif rendah dan mendukung kesejahteraan masyarakat sekitar (Ceballos, 1996).

Desa Sinar Hading merupakan salah satu desa yang terletak di Kecamatan Lewolema, Kabupaten Flores Timur, Provinsi Nusa Tenggara Timur. Desa Sinar Hading memiliki aset berupa pantai dan laut yang indah, antara lain Pantai Kawaliwu, Pantai Roga, dan Pantai Pasir Putih. Akan tetapi, di desa tersebut terdapat beberapa masalah yang mempengaruhi pengembangan potensi wilayahnya. Salah satu masalahnya adalah terbatasnya fasilitas penunjang ekowisata yang sesuai dengan prinsip pembangunan berkelanjutan. Jawaban atas masalah tersebut sangat penting untuk meningkatkan pelayanan ekowisata dan minat wisatawan baik dari daerah setempat maupun dari luar daerah.

Pengembangan destinasi ekowisata selama ini hanya dilakukan melalui media social seperti facebook oleh beberapa wisatawan yang pernah berkunjung ke lokasi tujuan dan lembaga pemerintah seperti Dinas Pariwisata dan Kebudayaan Kabupaten Flores Timur. Upaya ini tidak optimal karena belum menerapkan prinsip ekowisata yang komprehensif. Hal tersebut senada dengan pendapat Prasetia (2015) yang menyatakan salah satu faktor penghambat dari pengembangan ekowisata adalah aparat birokrat yang kurang menyosialisasikan program pengembangan ekowisata. Meskipun demikian, setiap tahun Dinas Pariwisata dan Kebudayaan bekerjasama dengan seluruh desa yang berada di Kecamatan Lewolema menyelenggarakan kegiatan Festival Nubun Tawa dengan anggaran dana yang cukup besar. Namun setelah kegiatan festival tersebut berakhir, maka berakhir pula kegiatan wisata di lokasi tersebut.

Ekowisata dengan menggunakan CBT sangat tepat untuk mengetahui kondisi wilayah dan sangat efektif dalam penggunaannya karena mencakup dimensi-dimensi yang lengkap. CBT tidak hanya mengkaji aspek ekonomi. CBT juga mencakup aspek sosial, budaya dan lingkungan. Penerapan CBT bermanfaat bagi berbagai pihak seperti pemerintah dalam menyusun strategi pemberdayaan ekonomi masyarakat (Rahayu et. al., 2016). Lembaga-lembaga swasta yang terkait dengan pariwisata dapat mengelola pariwisata sekaligus melestarikan budaya dan kesenian tradisional serta perbaikan sarana dan prasarana pariwisata (Pramusita dan Sarinastiti, 2017). Instansi seperti perguruan tinggi dapat melaksanakan pelatihan dan pembinaan sumber daya manusia (SDM) secara intensif kepada masyarakat desa terutama di bidang kepariwisataan, untuk mendorong keberhasilan dalam pembangunan desa wisata (Syafi'i dan Suwandono, 2015). Penelitian ini bertujuan untuk mengidentifikasi potensi-potensi ekowisata yang ada di Desa Sinar Hading Kecamatan Lewolema, menganalisis ekowisata dengan menerapkan CBT (Community Based Tourism), dan mengidentifikasi partisipasi masyarakat dalam pembangunan pariwisata.

\section{MATERI DAN METODE}

Beberapa sample diambil secara sengaja (purpossive sample) dari populasi masyarakat Desa Sinar Hading, Kecamatan Lewolema, Kabupaten Flores Timur. Desa Sinar Hading dipilih karena memiliki destinasi wisata budaya dan wisata bahari. Wisata budaya didukung oleh potensi budaya tenun ikat, rumah adat, tradisi inisiasi dan tarian perang. Wisata bahari didukung oleh keberadaan pantai Kawaliwu (Sunset beach of Kawaliwu), serta tempat pemandian air panas (sumber : Perdes Sinar Hading Nomor 4 Tahun 2019).

Penelitian ini menggunakan teknik observasi, wawancara dan penyebaran kuesioner untuk mengumpulkan data primer. Pengumpulan data dilakukan dengan menggunakan tiga instrumen yaitu (1) kuisioner yang berisi daftar pertanyaan tentang jenis, bentuk, gradasi dan aktivitas responden di dalam pembangunan pariwisata; (2) wawancara terbuka terhadap responden yang berkedudukan sebagai tokoh di dalam masyarakat. Data yang diperoleh menginformasikan pandangan, sikap dan deskripsi kesadaran masyarakat terhadap pembangunan pariwisata di 
daerahnya; (3) observasi non-partisipatif yaitu mengamati kehidupan sehari-hari masyarakat, dengan responden yang lebih variatif. Hal ini juga dilakukan oleh Syafi'i \& Suwandono (2015), dengan melakukan aktifitas yang sejalan dengan perencanaan dan penerapan CBT di antaranya adalah perintisan daya tarik wisata, pemantapan daya tarik wisata, aksesibilitas pariwisata, pembangunan prasarana umum, fasilitas umum dan fasilitas pariwisata peningkatan kualitas produk, serta daya saing.

Data berasal dari responden terseleksi (data primer) dan perpustakaan Desa Sinar Hading, serta media elektronik (data sekunder). Penentuan responden dilakukan dengan mengidentifikasi peranan dan kepentingan (interest) responden. Dari populasi masyarakat Desa Sinar Hading, dilakukan pengambilan sampel secara sengaja. Urutan responden dengan skala peranan serta kepentingan dari tingkat paling tinggi ke tingkatan paling rendah adalah : Kepala Desa dan perangkat pemerintah desa desa, Badan Permusyawaratan Desa (BPD), masyarakat di sekitar lokasi pantai, dan karang taruna. Waktu Penelitian dilaksanakan pada bulan Maret - April 2019.

Data yang diambil untuk melihat derajat partisipasi dan kesadaran terhadap pembangunan pariwisata dan sekaligus untuk memudahkan interpretasi. Metode pengumpulan data tersebut akan dibatasi dan berdasarkan aspek utama dalam pengembangan CBT. Menurut Suansri (2003) terdapat 5 dimensi: dimensi ekonomi, sosial, budaya, lingkungan dan politik. Namun penelitian ini hanya akan melihat dari empat dimensi saja yaitu ekonomi, sosial, budaya, dan lingkungan. Pada setiap dimensi disajikan 3 sub pertanyaan dengan pilihan positif (ada, mampu, tinggi) atau negatif (tidak ada, tidak mampu, rendah). Responden diminta memilih setuju atau tidak setuju (Syafi'i \& Suwandono, 2015)

\section{HASIL DAN PEMBAHASAN}

Perintisan daya tarik wisata dapat dilakukan dengan cara melakukan perencanaan dan perintisan pengembangan sarana dan prasarana dasar di kawasan yang belum berkembang agar dapat menjadi daya tarik wisata baru. Kualitas produk dan daya saing terhadap pembangunan daya tarik wisata juga harus berkesinambungan untuk meningkatkan kualitas kegiatan kepariwisataan di sektor lokasi daya tarik wisata. Hal tersebut senada dengan pendapat dari Handayani (2016) yang menyatakan bahwa peningkatan potensi daerah khususnya sektor pariwisata sangatlah penting dengan tujuan untuk meningkatkan pendapatan sektor pariwisata dan pendapatan daerah.

Pemerintah juga perlu melakukan penguatan interpretasi dan inovasi produk wisata, keunggulan kompetitif dan daya saing. Pada saat penelitian ini dilaksanakan, pemerintah daerah belum memberikan pelatihan tata kelola destinasi untuk mewujudkan CBT dan penyusunan detail visibility study dan detail engineering design daya tarik wisata. Partisipasi masyarakat dalam pengembangan usaha ekowisata pantai pun belum tampak. Terkait hal ini menurut Prasetia (2015), partisipasi masyarakat memiliki peran penting dalam pengembangan pariwisata sehingga tidak dapat sepenuhnya diserahkan kepada pihak pemerintah. Masyarakat harus aktif dan berinisiatif menertibkan, menjaga kesehatan dan konservasi lingkungan.

Usaha yang sudah dilakukan oleh pemerintah daerah hingga saat ini adalah memantapkan daya tarik wisata dengan atraksi wisata alam, budaya, dan buatan/khusus melalui Festival Nubun Tawa yang diadakan oleh pemerintah daerah Kabupaten Flores Timur setiap tahun masih di lingkup local. Pengembangan jejaring manajemen kunjungan terpadu dalam konteks nasional, regional, dan internasional belum dilakukan. Agung (2015) menyatakan bahwa pengemasan alam dan budaya masyarakat yang tepat dan kreatif melalui paket wisata yang menarik akan dapat menawarkan pengalaman langsung dengan kebudayaan lokal dan atraksi wisatanya.

Pengembangan prasarana dan infrastruktur dasar juga diperlukan untuk mendukung kesiapan kawasan pariwisata sebagai destinasi ekowisata. Hal tersebut meliputi penyediaan jaringan listrik dan lampu penerangan di sekitar area ekowisata, prasarana jalan menuju lokasi wisata, dan pembangunan jaringan telekomunikasi di kawasan ekowisata. Pengembangan sarana mode transportasi darat yang menghubungkan tiap koridor pariwisata daerah meliputi pengembangan kerjasama dengan perusahaan angkutan umum dan angkutan khusus milik pribadi masih dirasa sangat kurang memadai. Menurut Supriadi (2016) kelemahan-kelemahan yang terdapat pada daya tarik wisata (DTW) akan berdampak pada timbulnya kemiskinan di daerah 
tersebut karena masyarakat miskin ini sangat kompleks dan bersifat multidimensional dan berkaitan dengan aspek sosial, ekonomi, budaya, keamanan, dan aspek lainnya.

Faktor-faktor makro di atas mendukung pengembangan pariwisata di Desa Sinar Hading. Perlu ditekankan di sini bahwa prinsip pengelolaan pariwisata berkelanjutan tetap bertumpu pada partisipasi masyarakat. Hal tersebut selaras dengan pendapat Wiyandhita dan Koswara (2017) yang menyatakan bahwa peningkatan optimalisisasi meliputi faktor lingkungan, faktor sosial budaya, faktor pendidikan, faktor ekonomi, faktor kelembagaan, faktor keamanan dan faktor fasilitas dalam mendukung kegiatan wisata. Kajian-kajian dimensi berikut ini akan memberi gambaran tentang posisi masyarakat desa terhadap pariwisata.

Pada Tabel 1, persentase tertinggi ditempati oleh pelajar/mahasiswa yaitu $38,40 \%$ dan paling rendah adalah nelayan sebesar $0,17 \%$. Jumlah pelajar/mahasiswa yang tinggi didukung oleh mudahnya akses menuju pusat-pusat pendidikan. Hal yang menarik adalah persentasi penduduk yang tidak bekerja sebesar $22.58 \%$. Hal ini sebenarnya merupakan beban ekonomi yang tinggi. Meskipun demikian, masyarakat masih dibantu oleh beberapa program jaminan sosial dari pemerintah dan juga oleh hasil tanaman umur panjang yang ditanam oleh para generasi tua pada dekade 1990-2000. Jumlah petani (16.38\%) merupakan pilihan profesi yang disebabkan oleh berbagai alasan antara lain : kurangnya kompetensi diri, rendahnya tingkat persaingan menjadi petani di desa, tradisi, dan pilihan yang paling realistis bagi masyarakat yang memilih hidup di pedesaan. Persentase nelayan yang sangat rendah disebabkan karena nelayan merupakan pekerjaan sampingan untuk mencari lauk-pauk bagi keluarganya.

Sektor ekonomi Provinsi Nusa Tenggara Timur (NTT) masih didominasi oleh pertanian tradisional. Di sisi lain sektor-sektor yang memerlukan pengetahuan/keterampilan di Provinsi NTT jumlahnya masih cukup terbatas, tercermin dari porsi yang masih rendah terhadap perekonomian seperti industri pengolahan, informasi dan komunikasi, serta jasa keuangan dan asuransi (Tim Advisory dan Pengembangan Ekonomi KPW BI Provinsi NTT, 2019). Ekowisata berbasis masyarakat dapat menciptakan kesempatan kerja bagi masyarakat setempat, dan mengurangi kemiskinan. Penghasilan ekowisata berasal dari jasa-jasa wisata seperti fee pemandu, biaya transportasi, penyewaan homestay, menjual kerajinan, dan sebagainya (Pramono dan Lemy, 2019).

Tabel 1. Dimensi Ekonomi

\begin{tabular}{lrr}
\hline \multicolumn{1}{c}{ Jenis Pekerjaan } & Frekuensi & \multicolumn{2}{c}{ Persentase } \\
\hline Tidak bekerja & 264 & 22,58 \\
Nelayan & 2 & 0,17 \\
Wiraswasta & 21 & 1,80 \\
PNS & 10 & 0,85 \\
Pegawai swasta & 8 & 0,68 \\
Petani & 191 & 16,38 \\
Pelajar/mahasiswa & 449 & 38,40 \\
IRT & 224 & 19,14 \\
\hline \multicolumn{1}{c}{ Total } & 1.169 & 100 \\
\hline
\end{tabular}

Sumber : Perdes Sinar Hading Nomor 4 Tahun 2019

Hasil penelitian didapatkan bahwa jumlah penduduk laki-laki sebanyak 634 jiwa dan perempuan sebesar 655 jiwa. Dalam sebuah komunitas bertradisi patrilini, banyak pekerjaan lakilaki dibebankan kepada kaum perempuan. Hal ini menyebabkan dilematisme bagi masyarakat. Menerima pariwisata berarti menambah kerja baru bagi kaum perempuan. Akan tetapi, menolak pariwisata berarti menolak peningkatan pendapatan masyarakat. Kesadaran berbagi peranan sangat mutlak diperlukan dalam komunitas patrilini seperti ini. Kesadaran ini tentu saja dapat ditanamkan melalui lembaga pendidikan formal dan non formal yang ada. Hal tersebut menurut Aboe dan Ibrahim (2019) dapat diatasi dengan membentuk sebuah kelompok terpimpin dan pelatihan serta peningkatan capacity building terkait pemanfaatan lokasi wisata sehingga konsep CBT pada ekowisata dapat terlihat sehingga program konservasi, edukasi, dan pemberdayaan masyarakat bisa ditangani secara berkesinambungan. 
Tingkat pendidikan yang masih rendah (87.28\% berpendidikan SMP ke bawah) menyebabkan lambannya serapan inovasi di desa. Kurangnya pengetahuan terhadap teknologi baru menyebabkan rendahnya kemauan untuk mengadopsi inovasi. Menurut Larsen (2007) inovasi adalah sesuatu yang berkenaan dengan barang, jasa atau ide yang dirasakan baru oleh seseorang. Meskipun ide tersebut telah lama ada tetapi dapat dikatakan suatu inovasi bagi orang yang baru melihat atau merasakannya. Hadiyati (2011) menyatakan bahwa kebijakan pemerintah dalam pemberdayaan usaha kecil harus mempertimbangkan kreativitas dan inovasi dari seorang pengelola/pemilik usaha, hal ini akan mengefektifkan program kewirausahaan..

Sebanyak $57,74 \%$ persen masyarakat setuju untuk tetap mempertahankan budaya lokal seperti bahasa, tarian, ritual adat, minuman, dan perkawinan adat. Masyarakat memandang budaya sebagai pusat kehidupan. Hal tersebut senada dengan Yunus (2013) yang menyatakan bahwa globalisasi mempengaruhi hampir seluruh aspek kehidupan masyarakat termasuk diantaranya adalah aspek budaya. Menurut Suparno, et al., (2018) budaya lokal nusantara erat kaitannya dengan kebudayaan nasional sehingga maju mudurnya kebudayaan nasional sebagai budaya bangsa Indonesia tergantung pada eksistensi dari kebudayaan lokal (daerah).

Tabel 2. Dimensi Lingkungan

\begin{tabular}{lcc}
\hline & Frekuensi & Persentase \\
\hline Setuju & 620 & 53,04 \\
Tidak Setuju & 549 & 46,96 \\
Total & 1.169 & 100,00 \\
\hline
\end{tabular}

Pada Tabel 2 dapat dilihat bahwa sebanyak 53,04\% masyarakat setuju untuk kebersihan lingkungan dan bersedia untuk melakukan aktivitas secara berkala membersihkan pantai dari sampah laut namun sebanyak 46,96\% masyarakat kurang setuju dengan aktivitas tersebut dengan alasan bahwa sampah tersebut bukan mereka yang membuangnya ke laut melainkan sampah yang dibuang oleh kapal-kapal yang kemudian dibawa oleh arus. Keberadaan sampah dapat memiliki dampak negatif bagi ekosistem laut dan sekitarnya (Hammer et.al., 2012) ; (Hall et.al., 2015). Menurut Hall et.al. (2015), sampah plastik (makro) yang hancur menjadi mikroplastik dapat menjadi salah satu sumber makanan, dapat hancur dan masuk ke dalam jaringan mesentrial terumbu karang. Bila mikroplastik tersebut berasal dari bahan yang beracun dan masuk ke dalam tubuh biota laut (Andrady, 2011) maka ikan yang mengkonsumsinya akan mengalami gangguan kesehatan (Cole, 2011) hingga kerusakan hati (Rochman et.al., 2015). Potongan plastik dapat berpindah dari konsumen I ke konsumen ke II (Wright, 2013 ) dan akan berpindah pada manusia melalui proses rantai makanan (Farrell dan Nelson, 2013).

Pemerintah desa perlu mengelola sampah dengan baik dan mengubah pola pikir masyarakatnya agar sadar dalam menjaga alam sekitarnya mulai dari kepedulian terhadap sampah yang ada di lokasi pantai mereka. Menurut Iswandi (2015) isu-isu tentang pembangunan berkelanjutan telah berkontribusi pada pentingnya prinsip-prinsip pariwisata berkelanjutan. Prinsip pariwisata diharapkan untuk menjaga kualitas lingkungan, menjaga budaya, memberdayakan masyarakat lokal dan memberikan manfaat ekonomi bagi masyarakat lokal, daerah, dan pemerintah. Muallisin (2007), berpendapat bahwa faktor yang sangat penting bagi kesuksesan produk wisata untuk daerah pinggiran ialah melibatkan masyarakat dengan model pendekatan masyarakat.

\section{KESIMPULAN}

Potensi-potensi ekowisata di Desa Sinar Hading terdiri atas potensi alam, manusia, sosial, dan budaya yang semuanya memberikan dampak nyata bagi pariwisata. Dimensi-dimensi ekonomi, sosial, budaya, dan lingkungan saling berkaitan satu sama lain dan memengaruhi secara 
individual maupun secara kolektif. Usaha-usaha masyarakat masih berskala kecil dan bersifat sambilan dan belum merupakan usaha pokok meskipun berpotensi memajukan pariwisata apabila dikelola secara profesional.

\section{DAFTAR PUSTAKA}

Aboe, R.M. \& Ibrahim, M., 2019. Pengembangan Community-Based Tourism (Pariwisata Berbasis Masyarakat) di Kawasan Ekowisata Pantai Kastela Kota Ternate Selatan. Jurnal Pengamas, 2(1):45-53. ISSN: 2622-383X (online)

Andrady, A., 2011. Microplastics in the Marine Environment. Marine Pollution Bulletin, 62(8): 1596-1605. DOI: 10.1016/j.marpolbul.2011.05.030

Agung, A.G.A., 2015. Pengembangan Model Wisata Edukasi-Ekonomi berbasis Industri Kreatif Berwawasan Kearifan Lokal Untuk Meningkatkan Ekonomi Masyarakat. Jurnal IImu Sosial dan Humaniora, 4(2):585-59. DOI: 10.23887/jish-undiksha.v4i2.6380

Ceballos, L.H., 1996. Tourism, Ecotourism, and Protected Areas. Gland, Switzerland: IUCN.

Cole, M., Lindeque, P., Halsband, C. \& Galloway, T.S., 2011. Microplastics as Contaminants in the Marine Environment: a review. Marine Pollution Bulletin, 62(12):2588-2597. DOI: 10.1016/j. marpolbul.2011.09.025

Farrell, P. \& Nelson, K., 2013. Trophic Level Transfer of Microplastic: Mytilus edulis (L.) to Carcinus maenas (L.). Environmental Pollution, 177:1-3. DOI: 10.1016/j.envpol.2013.01.046

Hadiyati, E., 2011. Kreativitas dan Inovasi Berpengaruh Terhadap Kewirausahaan Usaha Kecil. Jurnal Manajemen dan Kewirausahaan, 13(1):8-16.

Handayani, A. F., 2016. Peningkatan Kualitas Pengelolaan Pantai Sembukan sebagai Daya Tarik Ekowisata Melalui Pemberdayaan Masyarakat. Economics Development Analysis Journal, 5(1):83-92. DOI: 10.15294/edaj.v5i1.22012

Hall, N.M., Berry K.L. Rintoul, L. \& Hoogenboom, M.O., 2015. Microplastic Ingestion by Scleractinian Corals. Marine Biology, 162:725-732. DOI: 10.1007/s00227-015-2619-7

Hammer, J., Kraak M.H.S. \& Parsons. J., 2012. Plastics in the Marine Environment: The Dark Side of a Modern Gift. Reviews of Environmental Contamination and Toxicology, 220:1-44. DOI: 10.1007/978-1-4614-3414-6_1

Larsen, P. \& Lewis, A., 2007. How Award Winning SMEs Manage The Barriers to Innovation. Journal Creativity and Innovation Management, 16(2):141-151. DOI: 10.1111/j.1467-8691. 2007.00428.x

Muallisin, I. 2007. Model Pengembangan Pariwisata Berbasis Masyarakat di Kota Yogyakarta. Jurnal Penelitian Bappeda Kota Yogyakarta. (2):5-15.

Pramusita, A. \& Sarinastiti, E.N., 2017. Aspek Sosial Ekonomi Masyarakat Lokal dalam Pengelolaan Desa Wisata Pantai Trisik, Kulonprogo. Jurnal Pariwisata Terapan, 2(1):14-25. DOI: $10.22146 /$ jpt.35378

Pramono, R. \& Lemy, D.M., 2019. Pengembangan Ekowisata Berbasis Masyarakat. Prosiding PKM-CSR. DOI: 10.37695/pkmcsr.v2i0.340

Prasetia, A.R., 2015. Partisipasi Masyarakat dalam Pengembangan Usaha Ekowisata Berbasis Pantai (Studi pada Dinas Pariwisata Kota Probolinggo). Jurnal Administrasi Publik, 3(7): 11971201.

Rahayu, S., Dewi, U. \& Fitriana, K. N., 2016. Pengembangan Community Based Tourism sebagai Strategi Pemberdayaan Ekonomi Masyarakat di Kabupaten Kulon Progo, Daerah Istimewa Yogyakarta. Jurnal Penelitian Humaniora, 21(1):1-13.

Rochman, C.M., Tahir, A., Williams, S.L., Baxa, D.V., Lam, R., Miller, J.T., Teh, F.C., Werorilangi, S. \& Teh, S.J., 2015. Anthropogenic debris in seafood: Plastic debris and fibers from textiles in fish and bivalves sold for human consumption. Scientific reports, 5, p.14340. DOI: 10.1038/ srep14340

Suansri, P., 2003. Community Based Tourism Handbook. Bangkok. Thailand: Responsible Ecological Social Tour-REST.

Suparno, S., Alfikar, G., Santi, D. \& Yosi, V., 2018. Mempertahankan Eksistensi Budaya Lokal Nusantara Ditengah Arus Globalisasi Melalui Pelestarian Tradisi Gawai Dayak Sintang. Jurnal Pekan, 3(1):43-56. DOI: 10.31932/jpk.v3i1.144 
Supriadi, B. 2016. Pengembangan Ekowisata Pantai sebagai Diversifikasi Mata Pencaharian. Jurnal Pariwisata Pesona, 1(1):1-20.

Syafi'i, M. \& Suwandono, D., 2015. Perencanaan Desa Wisata Dengan Pendekatan Konsep Community Based Tourism (CBT) Di Desa Bedono, Kecamatan Sayung, Kabupaten Demak. Ruang, 1(2):51-60. DOI: 10.14710/ruang.1.2.61-70

Iswandi, U., 2015. Analisis potensi pengembangan Ekowisata pantai mandeh kabupaten Pesisir selatan. Jurnal Spasial: Penelitian, Terapan IImu Geografi, dan Pendidikan Geografi, 4(2):p.131003. DOI: 10.22202/js.v2i2.1587.g894

Wiyandhita, D.P. \& Koswara, A.Y., 2017. Faktor - Faktor Pengembangan Ekowisata Pada Pantai Pathok Gebang dan Ujung Pakis di Desa Jengglungharjo. Jurnal Teknik ITS, 6(2):C339-C342. DOI: 10.12962/j23373539.v6i2.27940

Wright, S.L., Thompson R.C \& Galloway T.S., 2013. The Physical Impacts of Microplastics on Marine Organisms: a review. Environmental Pollution, 178:483-492. DOI: 10.1016/j.envpol. 2013.02.031

Yunus, R., 2013. Transformasi Nilai-nilai Budaya Lokal sebagai Upaya Pembangunan Karakter Bangsa. Jurnal Penelitian Pendidikan, 13(1):67-79. 